\title{
La Violencia contra la Mujer en el Marco de las Relaciones de Parejas o Ex parejas Sentimentales: un Análisis de las Políticas Criminales en Colombia desde una Óptica Criminológica
}

\author{
Violence against Women in the Framework of Relationships of Couples or Sentimental Ex- \\ Couples: an Analysis of Criminal Policies in Colombia from a Criminological Optics \\ ${ }^{a}$ Natalia Andrea Julio Estrada, Melisa Andrea Arroyo Valeta ${ }^{63 b}$ \\ a angeldavid-1997@hotmail.com “Semillero Justicia, Política y Derecho", "Grupo de Investigaciones Jurídicas y Socio jurídicas”, Programa de \\ Derecho, Fundación Universitaria Tecnológico Comfenalco. Cartagena, Colombia. \\ bangeldavid-1997@hotmail.com "Semillero Justicia, Política y Derecho", "Grupo de Investigaciones Jurídicas y Socio jurídicas”, Programa de \\ Derecho, Fundación Universitaria Tecnológico Comfenalco. Cartagena, Colombia.
}

Forma de Citar: N.A. Julio-Estrada; M.A. Arroyo-Valeta, "La Violencia contra la Mujer en el Marco de las Relaciones de Parejas o Ex parejas Sentimentales: un Análisis de las Políticas Criminales en Colombia desde una Óptica Criminológica”, Rev. Saberes, Vol. 13, No. 02, pp. 88 - 92 , 2020.

Recibido: 24/03/2020 Evaluación: 28/05/2020 Aceptado:30/06/2020 DOI: https://doi.org/10.25213/1794-4384/1302.0012

\section{Resumen}

El contexto en el que se presenta la violencia contra la mujer es comprendido desde las esferas públicas y privadas, los cuales han permitido tener una concepción del tema y por tal motivo diseñar unas políticas criminales como respuesta estatal al fenómeno; sin embargo, las bases que han cimentado la creación de estas políticas no han comprendido el impacto social que genera esta violencia. Es por ello, que se acude a la criminología crítica para explicar el enfoque social del daño que genera el crimen, no obstante, la mirada que se le ha dado a este fenómeno en el campo de las parejas y ex parejas sentimentales, ha sido poco desarrollada, limitándose al concepto de desigualdad o asimetría que socialmente ha marcado la relación hombre-mujer.

Por tal motivo resulta complejo la creación de una política criminal que abarque toda la dimensión de la violencia contra la mujer, recalcando que la desigualdad solamente es una pequeña arista al problema que de verdad supone este tipo de violencia, dado que únicamente se está mirando la punta del iceberg.
Palabras claves

Violencia contra la mujer, parejas y ex parejas, enfoque del daño, criminología, desigualdad.

\begin{abstract}
The context of violence against women is understood from the public and private spheres, which have allowed us to have a conception of the issue and for that reason design criminal policies as a state response to the phenomenon; However, the foundations that have cemented the creation of these policies have not understood the social impact generated by this violence. That is why, critical criminology is used to explain the social approach to the damage caused by crime, however, the look that has been given to this phenomenon in the field of couples and former partners, has been little developed, limiting itself to the concept of inequality or asymmetry that has socially marked the relationship between men and women.
\end{abstract}

For this reason, it is complex to create a criminal policy that covers the entire dimension of violence against women, emphasizing that inequality is only a small edge to the problem that this type of

\footnotetext{
* Autor para correspondencia: correo electrónico angeldavid-1997@hotmail.com 
violence really entails, given that it is only looking at the tip of the iceberg.

\section{Keywords}

Violence against women, couples and former partners, harm approach, criminology, inequality.

\section{Epígrafe}

"Una se avergüenza de ser la víctima de un hombre asi y se abandona a una total soledad e impide a todos que se acerquen, incluso a sus propios hijos, porque una no quiere que nadie mueva un dedo, y menos que nadie ellos. $Y$ allí se queda esperando el próximo ataque, que llegará sin aviso alguno, y está llena de odio hacia algo que no comprende, y la vida entera se convierte en la espera del siguiente ataque, ¿Cuándo llegará?, ¿cuánto daño le hará?, ¿cuál será el motivo?, ¿cómo evitarlo?” (Indridason, 2001).

\section{Introducción}

El siguiente trabajo tiene como fin, generar una reflexión sobre el conjunto de políticas criminales que combaten la violencia contra la mujer en las relaciones de parejas y ex parejas en Colombia desde una óptica criminológica, para llegar a esto es necesario analizar la limitación existente en el discurso de "desigualdad" que justifica la creación de políticas criminales que combaten la violencia contra la mujer en las relaciones de parejas y ex parejas, de esta manera, explicar el enfoque del daño social que genera la violencia contra la mujer en Colombia.

Lo presentado en el epígrafe anterior es para ilustrar una de las formas de violencia contra la mujer, generada por sus pareja o expareja sentimental, la cual no solamente atañe a una violencia física, sino que también incluye la violencia sexual y psicológica, consiguiendo así no solamente la configuración de lesiones personales, sino que también conlleva a una de las lecturas del feminicidio. Esta relación de estos dos delitos se debe a que en Colombia existen políticas criminales que regulan el tema de una forma reactiva (tienen como fin una pena determinada para el victimario) y no políticas criminales preventivas que permitan comprender la complejidad del fenómeno.
En ese sentido, un asunto muy particular que vale la pena mencionar, es el de los roles de género y la brecha que permite la desigualdad que existe y que ha sido construida social y culturalmente, en la que el hombre es el que impone la coerción sexual, o que puede por su "masculinidad" cometer intimidaciones de tipo sexual, hasta llegar al punto de las confusiones de tipo violento, es decir aumentar su hombría con violencia sexual hacia la mujer. En ocasiones, esta violencia es ejercida porque se busca un tipo de control por parte de la pareja y quien reciba este control trata de cumplirlo para evitar tensiones en la relación (Johnsen, 2005, pág. 3).

La importancia de este trabajo es generar reflexiones en el campo académico y social, el primero atendiendo a las necesidades de debatir los alcances de la criminología critica como forma de comprender el daño social que genera el delito y como disciplina que sienta las bases para la elaboración de políticas criminales en un país y que por tanto debe permear todas las dimensiones del daño social. El segundo entender las implicaciones sociales de la violencia contra la mujer en Colombia. Lo anterior obedece al interrogante ¿Qué tan eficaces son las políticas criminales en Colombia que combaten la violencia contra la mujer en las relaciones de parejas o ex parejas sentimentales?

\section{Metodología}

La presente ponencia sienta sus bases en el enfoque cualitativo de investigación el cual plantea una descripción detallada de situaciones, eventos, personas, interacciones y comportamientos que son observables (Villegas Tamara, Ferrer Araujo, \& Acosta Castro, 2018); Es en esta línea que el texto ofrece la descripción de un fenómeno observable como la violencia contra la mujer desde una mirada criminológica. De esta forma, el tipo de investigación empleada es la investigación socio-jurídica que tiene como finalidad entender la realidad social a partir de las instituciones jurídicas (Sampieri, 2018); Por tanto, el texto logra explicar que el sistema penal colombiano en materia de políticas criminales puede ser un poco incompleto. Asimismo, se recolectó información bibliográfica por medio de textos, los cuales permitieron emplear el método hermenéutico, el cual busca la interpretación de textos y darle sentido a los

Página | 89 
mismos (Villegas Tamara, Ferrer Araujo, \& Acosta Castro, 2018). De este modo, este método permitió asumir la posición que se toma en el texto.

\section{Discusión del Tema}

1. Limitación en el discurso de "desigualdad" de violencia de parejas y ex parejas en el marco de la violencia de género.

La violencia contra la mujer presentada en el contexto de la violencia de parejas o ex parejas sentimentales ha sido un fenómeno que ha tenido distintas maneras en las que se ha cimentado, desde un inicio como un hombre que maltrata a su pareja por causas externas, a una concepción actual entendida como una causal única y equivoca de discriminación, desigualdad y sujeción de la mujer. (Larrauri, 2018).

Es necesario resaltar que la desigualdad es un tema que de una $u$ otra manera toca a las mujeres en la mayoría de los ámbitos de la vida, como lo expresa dobash y dobash (Dobash, 2000) al presentar de manera general que este es un el elemento estructural del patriarcado, que se puede evidenciar en la jerarquía que ocupa al mujer dentro del hogar y en las distintas instituciones tanto económicas como educativas y políticas. Teniendo así una arista ideológica que permite una legitimación de la dominación masculina. Con base a esto es fácil llegar a la conclusión de que la responsabilidad de la victimización en las relaciones de parejas es netamente culpa de la desigualad.

En este sentido, la violencia contra la mujer en las relaciones de pareja se ha simplificación a tal punto de ser presentado como un delito que se reduce al simple hecho de ser mujer, como si esta sujeción fuese una causa suficiente para explicar la violencia, en esta misma línea determinando de manera excesiva la desigualdad de género la cual se le apropia la causa fundamental para este tipo de violencia , como si la desigualdad que se presenta tuviera la capacidad suficiente para minimizar otros tipos de desigualdad y agudizar la victimización , como punto final dejando la exhaustiva tarea al derecho penal para que entre a cambiar esta desigualdad a la que como se mencionó anteriormente se le ve como la principal responsable de la victimización.

\section{Carencias del discurso de desigualdad desde la criminología.}

Con base a todo lo planteado anteriormente, se puede abordar la implicación de la criminología, pensando en la explicación causa-motivo y las maneras de prevención de este fenómeno (Zaffaroni, 2012). Sin embargo, si se limita el fenómeno de la violencia contra la mujer al discurso de desigualdad, se estarían ignorando otras particularidades del mismo; En razón de que la forma en la que las normas etiquetan el daño o la protección de los bienes jurídicos pueden llegar a ser insuficientes y existiría una concepción reduccionista del daño que genera esta violencia.

Bajo este marco, la criminología crítica encuentra sentido por ejemplo, en el análisis de la pobreza como el último atisbo de la delicuencia y de la misma forma, se podría relacionar este análisis con la prespectiva de género debido a que siempre se acude al patriarcado para la explicación de este fenómeno y si en el primer análisis que se ha hecho desde la criminología encontró su complejidad de trasmisión a la sociedad, también resulta complejo explicar desde la perspectiva de género el por qué no todas las mujeres son víctima. Si se presentara una línea constante en la subordinaciónvictimizacion "no haría falta ninguna teoría criminológica" para explicarlo (Larrauri, 2018).

Teniendo en cuenta que lo anterior no sucede, se entiende que desde la criminología, de momento no se ha podido aclarar estas implicaciones del daño social que genera la insuficiencia de la protección de bienes jurídicos que evitan la violencia contra la mujer. Pues, no se logra aclarar elementos importantes de cómo no todas las mujers tienen el riesgo de ser víctimas y lo más importante del asunto, el por qué ser mujer es un factor de alto riesgo en la relaciones de pareja o ex pareja. Entonces, al carecer de este análisis desde la criminología y además omitir este discurso de género, se estarían construyendo unas políticas criminales y leyes basadas es una perspectiva reduccionista.

\section{Enfoque del Daño Social en la Violencia contra la Mujer en Colombia.}

Lo anterior supone que se comience a hablar de políticas criminales, las cuales tienen

Página | 90 
implicaciones en la normatividad de un país y en la forma en cómo se abordan los fenómenos que se presentan desde las conductas desviadas o por fuera de la norma.

Ahora, el nuevo debate de la criminología tiene un sentido más estricto del crimen y es: "El enfoque del daño social", pues ya no se busca estudiar el crimen sino la reacción social del mismo (Cohen, 2005). Si el abordaje del enfoque social no está incluyendo un fenómeno que ya se encuentra visibilizado como la violencia contra la mujer, puede dar cuentas de que, aun existiendo políticas criminales en un país, no se harán visibles las magnitudes que genera este fenómeno en la sociedad. Lo anterior, bajo el supuesto de que la creación de las políticas criminales en un estado depende del enfoque criminológico que se tenga del delito (Rivera, 2005).

Si bien en Colombia, existen lineamientos para la creación de políticas criminales que buscan combatir la violencia contra la mujer, los cuales se basan en la lógica de la relación asimétrica entre el hombre y la mujer o en otras palabras la condición de desigualdad entre estos. Dichas políticas criminales han incidido en la forma en cómo actualmente se protege a la mujer o en su defecto, se repara en el evento en que sea víctima de violencia; Sin embargo, de acuerdo a cifras dadas por medicina legal (Medicina Legal , 2019) existe un volumen considerable de casos que dan cuenta del poco abordaje de tales políticas. De hecho, la corporación cisma mujer creó un lineamiento para esta creación de políticas criminales que vuelve a mencionar que existe una condición de inferioridad entre una mujer y hombre, por los patrones socioculturales y estereotipos de género que sin duda son el motor principal para la violencia contra la mujer (Corporación Cisma Mujer, 2013); No obstante, la reacción social que genera la violencia contra la mujer va mucho más allá de eso, implica entender que esta violencia pasó de un plano privado al plano público porque también llega a convertirse en un tema de orden público, de salud pública tanto física como psicológica y que la sociedad Colombiana deber ver como una verdadera problemática y no como una simple amplificación de un fenómeno. Y así como este lineamiento, también se encuentran las mismas políticas criminales como la ley
$1257 / 2008$, la $1761 / 15$ que crea el feminicidio como tipo penal autónomo y en su defecto el artículo 104 del código penal. Las cuales sintetizan el problema a la alusión "Por el hecho de ser mujer" y bajo esa premisa se infiere que se trata de violencia contra la mujer.

Con base a lo anterior, que menciona aquello que la criminología no abarca dentro de ese enfoque social al que actualmente le apuntan sus debates; Es posible afirmar que las políticas criminales que existen para combatir la violencia contra la mujer en Colombia, pueden tener su insuficiencia en la forma en la que se etiqueta el daño social que genera, pues los bienes jurídicos que se buscan proteger en las normas que regulan este tema no alcanzan a explicar la complejidad del fenómeno. Esta reflexión es la que en principio conlleva a entender por qué aun existiendo políticas proteccionistas de los derechos humanos de la mujer, siguen presentándose numerosos casos de esta violencia. Toda vez que, se está invisibilizando la magnitud del fenómeno y es que en la creación y formulación de políticas criminales que combaten la violencia contra la mujer, no se hace el abordaje criminológico de esta violencia.

Como base fundamental de los argumentos anteriores, se encuentra el boletín epidemiológico del 2019 dado por medicina legal que da cuenta del volumen de casos que se presentan de violencia contra la mujer provocada por su pareja o ex pareja sentimental, aclarando que en la mayoría de los feminicidios los actores principales son parejas o ex parejas sentimentales (Medicina Legal , 2019).

Figura No 1. Boletín epidemiológico 2018-2019 64

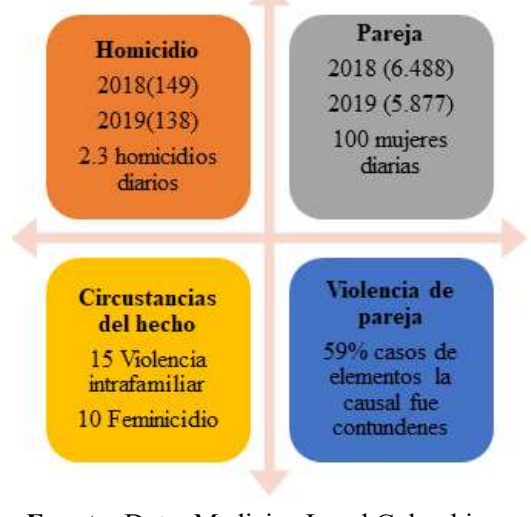

Fuente: Dpto. Medicina Legal Colombia.

\footnotetext{
${ }^{64}$ Boletín informativo medicina legal.
} 


\section{Conclusiones}

- Dentro del conflicto armado interno colombiano la mujer ha desempeñado un importante papel que se enmarca en la victimización de su género debido a que durante más de cincuenta años ha sido blanco directo de vulneraciones y transgresiones con respecto a sus derechos y libertades fundamentales (Ayala, E. T., y Osorio, E. G. ,2016)

- La limitación de la responsabilidad victimizante es las relaciones de parejas y exparejas, da como resultado un abordaje criminológico poco íntegro porque no analiza todos los enfoques del daño social.

- Lo anterior para entender que las políticas criminales que buscan erradicar la violencia contra la mujer en el contexto de parejas y exparejas sentimentales no abarcan todo lo concerniente al fenómeno.

- En colombia, las políticas criminales que existen tienen como fin la pena del victimario y no la protección de los bienes jurídicos que amparan los derechos de la mujer.

\section{Referencias Bibliográficas}

Ayala, E. T., y Osorio, E. G. (2016). La mujer como víctima y actor del conflicto armado en Colombia. Perspectivas. 1(1). 73-80.

Cohen, S. (2005). Estados de negación. Buenos Aires: Albremática.

Corporación Cisma Mujer. (11 de mayo de 2013). Biblioteca digital unal. Obtenido de http://bdigital.unal.edu.co/48736/1/97895886080

$\underline{51 . p d f}$

Dobash, E. (2000). Home truths about domestic violence. Nueva york: Routlege. Estudio criminal. (20 de febrero de 2020). Estudio criminal. Obtenido de https://www.estudiocriminal.eu/criminologia/

Indridason, A. (2001). La mujer de verde. Reikiavik: RBA.

Johnsen, J. (2005). El maltrato en las relaciones, la violencia contra la peja íntima y para la sociedad. Nueva York: Planned Parenthood.
Larrauri, E. (2018). Criminología crítica y violencia de género. España: Trotta.

Medicina Legal. (2019). Cifras de violencia contra la mujer 2018-19. Bogotá.

Rivera, I. (2005). Política criminal y sistema penal. Barcelona: Anthropos Editorial.

Sampieri, R. (2018). Metodología de la investigación, rutas cuantitativas, cualitativas y mixtas. Nueva York: Mcgraw-Hill.

Villegas Tamara, D., Ferrer Araujo, N., \&amp; Acosta Castro, J. (2018). Metodología de la investigación jurídica y socio-jurídica. Cartagena: Bonaventuriana.

Zaffaroni, E. (2012). La cuestión criminal. Barcelona: Planeta. 